\title{
Helposti puhdistettava lattia - hoitajien ja eläinten turvallisuustekijä
}

\author{
Maarit Puumala ${ }^{1)}$, Pekka Jauhiainen ${ }^{1)}$, Riitta Mahlberg' ${ }^{2)}$, Liisa Salparanta ${ }^{2)}$, Hanna-Riitta Kymä- \\ läinen ${ }^{3)}$, Jenni Määttä ${ }^{3)}$, Risto Kuisma ${ }^{3)}$, Anna-Maija Sjöberg ${ }^{3)}$ \\ ${ }^{1)}$ Maa- ja elintarviketalouden tutkimuskeskus MTT, Kotieläintuotannon tutkimus, Vakolantie 55, 03400 \\ Vihti,maarit.puumala@mtt.fi; pekka.jauhiainen@mtt.fi \\ ${ }^{2)}$ Valtion teknillinen tutkimuskeskus VTT,Uudet materiaalit, Pl 1000, 02044 VTT, \\ riitta.mahlberg@vtt.fi; liisa.salparanta@vtt.fi \\ ${ }^{3)}$ Helsingin yliopisto, Agroteknologian laitos, Pl 28 (Koetilantie 3), 00014 Helsingin yliopisto, hanna- \\ riitta.kymalainen@helsinki.fi;,_jenni.maatta@helsinki.fi; risto.kuisma@helsinki.fi; anna- \\ maija.sjoberg@helsinki.fi
}

\section{Tiivistelmä}

Tuotantotilojen likaiset ja kosteat lattiat aiheuttavat liukastumisriskin niin eläimille kuin niiden hoitajille. Paitsi lattioiden oikealla muotoilulla, voidaan niiden kuivana sekä puhtaana pysymiseen vaikuttaa materiaalivalintojen avulla. Betoni on yleisin tuotantotiloissa käytetty lattia-, ja päällystemateriaali. Betoni on huokoinen materiaali. Huokoisuudesta johtuen tuotantotilojen epäpuhtaudet ja lika-aines imeytyvät helposti betoniin.

Uusien ja perinteisten navetan pintamateriaalien puhdistuvuutta ja ominaisuuksia on tutkittu Maa- ja metsätalousministeriön rahoittamassa kolmevuotisessa tutkimushankkeessa "Helposti puhdistettavat pinnat maatilarakentamisessa". Hankkeessa keskityttiin olemassa olevien pinnoitteiden lianhylkivyyteen ja kulutuskestoon vaikuttavien tekijöiden kartoittamiseen ja pinnoitettujen tuotteiden käyttöiän arvioimiseen. Pintamateriaalien ominaisuuksia on tutkimuksen aiemmissa vaiheissa selvitetty laboratoriokokein. Koska materiaalien soveltuvuutta kotieläintiloihin ei voida selvittää pelkästään laboratoriossa, tuloksia on varmennettu käytännön kokeella.

Kenttäkoe perustettiin osin uuteen ja osin peruskorjattuun pihattoon vuoden 2006 lopulla. Tutkittavana oli verrokkina toimineen teräshierretyn betonin rinnalle perinteisistä navetan pintamateriaaleista polyesteribetoni, tiivis asfaltti ja karhennetut epoksi-, polyuretaani- ja akryylipinnoitteet sekä tässä ympäristössä uudenlaiset materiaalit silaani-impregnointi ja öljypohjainen pinnoite sekä sellaisenaan että kumirouheella täytettynä. Halutut materiaalien pintaominaisuudet mitattiin ennen kokeen alkua, 3 kk, 6 kk ja 9 kk kokeen alusta sekä viimeisen kerran kenttäkokeen päätyttyä marraskuussa 2007. Kentällä mitattuja pintaominaisuuksia olivat pinnan topografia, pinnan väri ja kiiltoa. Lisäksi kokeen alussa, 6 kk:n ikäisinä ja kokeen päätyttyä koekappaleet punnittiin laboratoriossa ja niistä määritettiin pinnan hylkivyys ja puhdistettavuus.

Seurantajakson aikana lattialle sijoitettujen materiaalien pinnan korkeushuiput ja syvimmät kolot tasaantuivat. Ruokintapöydän materiaalien syvimmät kolot tasaantuivat, mutta huippujen tasaantumista ei ollut havaittavissa. Vastaavasti lattiapintanäytteiden kiilto keskimäärin hieman kasvoi tai pysyi lähes muuttumattomana, kun ruokintapöydän pintanäytteiden kiilto useimmissa tapauksissa aleni. Kaikki lattian koepalat pinttyivät ja tummuivat tasaisesti kenttäkokeen edetessä, mutta huokoiset teräshierretty ja silaani-impregnoitu betoni erottuivat muovipinnoitteista huonomman kosteuden hylkivyyden perusteella. Muista pintamateriaaleista poiketen, toinen öljypohjaisista lattiapinnoitteista kului koejakson aikana osin puhki.

Asiasanat: eläinsuojat, lattia, pintaominaisuudet, topografia, kiilto, väri 


\section{Johdanto}

Maatilojen tuotantorakentamisella on tarkoitus luoda hyvät ja tarkoituksenmukaiset olosuhteet rakennuksen käyttäjille, tuotantotoiminnalle ja tuotantoeläimille. Maataloustuotannossa on pyrkimyksenä laadukkaan elintarvikkeen tuottaminen. Tällöin myös tuotanto-olosuhteiden ja siten myös tuotantorakennusten tekninen laatutasovaatimus on noussut niin eläinten hyvinvoinnin, työturvallisuuden, hygienian kuin ympäristönhoidonkin osalta.

Tuotantorakennusten materiaalivalinnat ovat yksi eläinten hyvinvointiin (Baxter 1984), työntekijöiden työskentelymukavuuteen ja tuotantotilojen hygieeniseen tasoon vaikuttava tekijä (McClanahan 2005). Tuotantotilojen likaiset ja kosteat lattiat aiheuttavat liukastumisriskin niin eläimille kuin niiden hoitajille. Paitsi lattioiden oikealla muotoilulla, voidaan niiden kuivana sekä puhtaana pysymiseen vaikuttaa materiaalivalintojen avulla. Betoni on yleisin materiaali sikaloiden kiinteissä ja rakolattioissa (De Belie 1997). Betoni on myös yleisin muissa kotieläintuotantotiloissa käytetty lattiaja päällystemateriaali. Betoni on huokoinen materiaali. Huokoisuudesta johtuen tuotantotilojen epäpuhtaudet ja lika-aines imeytyvät helposti betoniin.

Teknologian kehittymisen myötä nanoteknologiaan ja funktionaalisiin polymeereihin perustuvilla pinnoitustekniikoilla voidaan räätälöidä perusmateriaalin pintaominaisuuksia halutuiksi. Erityisen lupaavia tuloksia on saatu betonin osalta. Betonipinta voidaan käsitellä esimerkiksi hydrofobisella impregnointiaineella siten, että pinta hylkii likaa tai on helposti puhdistettavissa pelkällä vedellä. Lattiapintojen kohdalla on etu, että impregnointikäsittely ei lisää pinnan liukkautta. Betonin pinnoitteilla voidaan saada aikaan hyvin kemiallista ja mekaanista kulutusta kestäviä pintoja. Kokemusten mukaan helposti puhdistettavat pinnat ovat oikein käytettynä myös taloudellisesti kannattavia.

Uusien ja perinteisten navetan pintamateriaalien puhdistuvuutta ja ominaisuuksia on tutkittu Maa- ja metsätalousministeriön rahoittamassa tutkimushankkeessa "Helposti puhdistettavat pinnat maatilarakentamisessa". Pintamateriaalien ominaisuuksia on tutkimuksen aiemmissa vaiheissa selvitetty laboratoriokokein (Määttä et al. 2007a,b ja 2008). Koska materiaalien soveltuvuutta kotieläintiloihin ei voida selvittää pelkästään laboratoriossa, tuloksia on varmennettu käytännön kokeella.

\section{Aineisto ja menetelmät}

Laboratoriokokeiden tulosten (Määttä et al. 2007a,b) perusteella valittiin 8 pintamateriaalia (taulukko 1). Erilaisten pintakäsittelyjen ja pinnoitteiden verrokkina oli tuotantorakennuksissa yleisimmin käytetty lattiamateriaali, teräshierretty betoni. Koepalat $\left(100 \times 100 \mathrm{~mm}^{2}\right.$, neljä kerrannetta) asetettiin kehikkoihin, jotka asennettiin pihaton ruokintapöydälle ja lattialle (kuva 1).

Taulukko 1. Kenttäkokeeseen laboratoriokokeiden perusteella valitut materiaalit (X)

\begin{tabular}{llccc}
\hline Perusmateriaali & Käsittely & Lyhenne & \multicolumn{2}{c}{ Sijoituskohde } \\
\cline { 3 - 5 } & & & Lattia & Ruokintapöytä \\
\hline \multirow{2}{*}{ Betoni } & Teräshierretty & BE & $\mathrm{X}$ & $\mathrm{X}$ \\
& Epoksi + hiekka & EP & $\mathrm{X}$ & $\mathrm{X}$ \\
& Silaani-impregnointi & LA & $\mathrm{X}$ & $\mathrm{X}$ \\
& Akryyli + hiekka & $\mathrm{AK}$ & $\mathrm{X}$ & $\mathrm{X}$ \\
& Polyuretaani + hiekka & PUR & $\mathrm{X}$ & $\mathrm{X}$ \\
& Öljypohjainen pinnoite & ÖL & $\mathrm{X}$ & - \\
& Öljypohjainen pinnoite +kumi & ÖK & $\mathrm{X}$ & - \\
\hline Polyesteribetoni & Tehdasvalmisteinen & PE & - & $\mathrm{X}$ \\
\hline
\end{tabular}

Kenttäkoe käynnistettiin joulukuussa 2006 asentamalla ruokintapöydän materiaalit kohteeseen. Lattian älyporttiin koepalat asennettiin tammikuussa 2007. Koemateriaaleista tehdyt ominaisuusmittaukset ja niiden aikataulu on esitetty taulukossa 2. Koska lattian koemateriaalien asennus tehtiin myöhemmin kuin ruokintapöydän, jää niiden seurantajakso 9 kk:n mittaiseksi. Koepalat punnittiin 65 \%:n suhteellisessa kosteudessa $\left(20^{\circ} \mathrm{C}\right)$ tasaannutuksen jälkeen. Pinnan topografia on mitattu Micro-Epsilon ILD1400-100 laserprofilometrillä. Väri mitattiin Minolta Chroma Meter CR-210 värimittarilla 5 kohdasta, kiilto Picogloss 503-mittarilla 5 kohdasta $\left(85^{\circ}\right)$. Kustakin koekappaleesta tehdään 3-5 mittausta tutkimusmenetelmästä riippuen. 


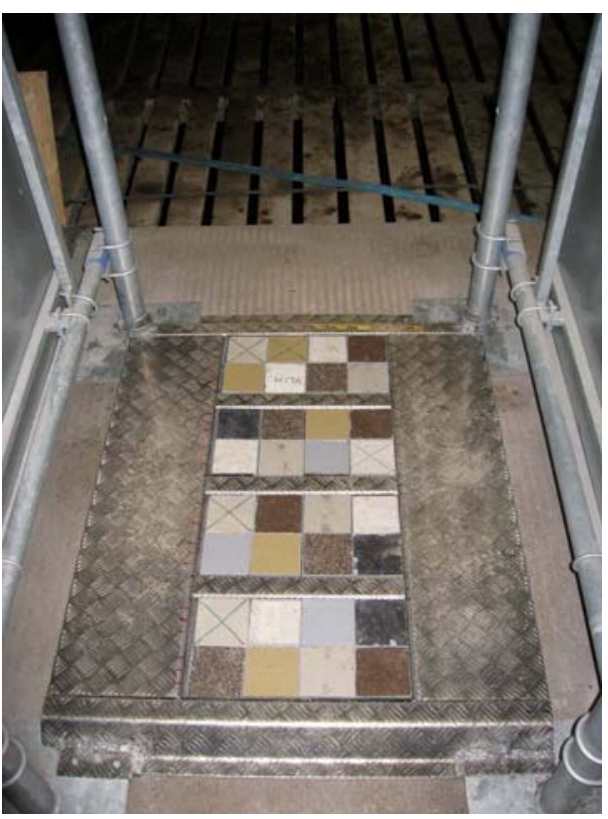

Taulukko 2. Koemateriaalien mittaukset (X) ja niiden ajoitus.

\begin{tabular}{llllll}
\hline Mitattu & \multicolumn{5}{c}{ Mittausajankohta } \\
\cline { 2 - 6 } parametri & $\begin{array}{l}\text { Kokeen } \\
\text { aloitus }\end{array}$ & $\begin{array}{l}3 \\
\mathrm{kk}\end{array}$ & $\begin{array}{l}\mathrm{kk} \\
\mathrm{X}\end{array}$ & $\begin{array}{l}\mathrm{kk} \\
\mathrm{X}\end{array}$ & $\begin{array}{l}12 \mathrm{kk}, \\
\text { kokeen } \\
\text { päätös }\end{array}$ \\
\hline Paino & $\mathrm{X}$ & - & $\mathrm{X}$ & - & $\mathrm{X}$ \\
\hline $\begin{array}{l}\text { Pinnan } \\
\text { topografia }\end{array}$ & $\mathrm{X}$ & $\mathrm{X}$ & $\mathrm{X}$ & $\mathrm{X}$ & $\mathrm{X}$ \\
\hline Väri & $\mathrm{X}$ & $\mathrm{X}$ & $\mathrm{X}$ & $\mathrm{X}$ & $\mathrm{X}$ \\
\hline Kiilto & $\mathrm{X}$ & $\mathrm{X}$ & $\mathrm{X}$ & $\mathrm{X}$ & $\mathrm{X}$ \\
\hline Hylkivyys & $\mathrm{X}$ & - & - & - & $\mathrm{X}$ \\
\hline $\begin{array}{l}\text { Puhdis- } \\
\text { tettavuus }\end{array}$ & $\mathrm{X}$ & - & - & - & - \\
\hline - ei mitattu & & & & & \\
\hline
\end{tabular}

Kuva 1. Lattialle älyportin kohdalle asennettu koemateriaalikehikko.

\section{Tulokset ja tulosten tarkastelu}

Laserprofilometrillä mitatut pinnan korkeimpien huippujen ja syvimpien kuoppien keskiarvot sekä ruokintapöydältä että lattialta on esitetty kuvassa 2. Sekä lattialla että ruokintapöydällä koemateriaalien syvimmät kuopat olivat madaltuneen, mihin vaikutti paitsi pinnan kuluminen, myös lian kerääntyminen syvennyksiin. Lattialla pinnan korkeimmat huiput olivat alentuneet, mutta samaa ei ollut havaittavissa ruokintapöydän pinnoissa. Vastaavasti lattiapintanäytteiden kiilto keskimäärin hieman kasvoi tai pysyi lähes muuttumattomana, kun ruokintapöydän pintanäytteiden kiilto useimmissa tapauksissa aleni (Taulukko 3).
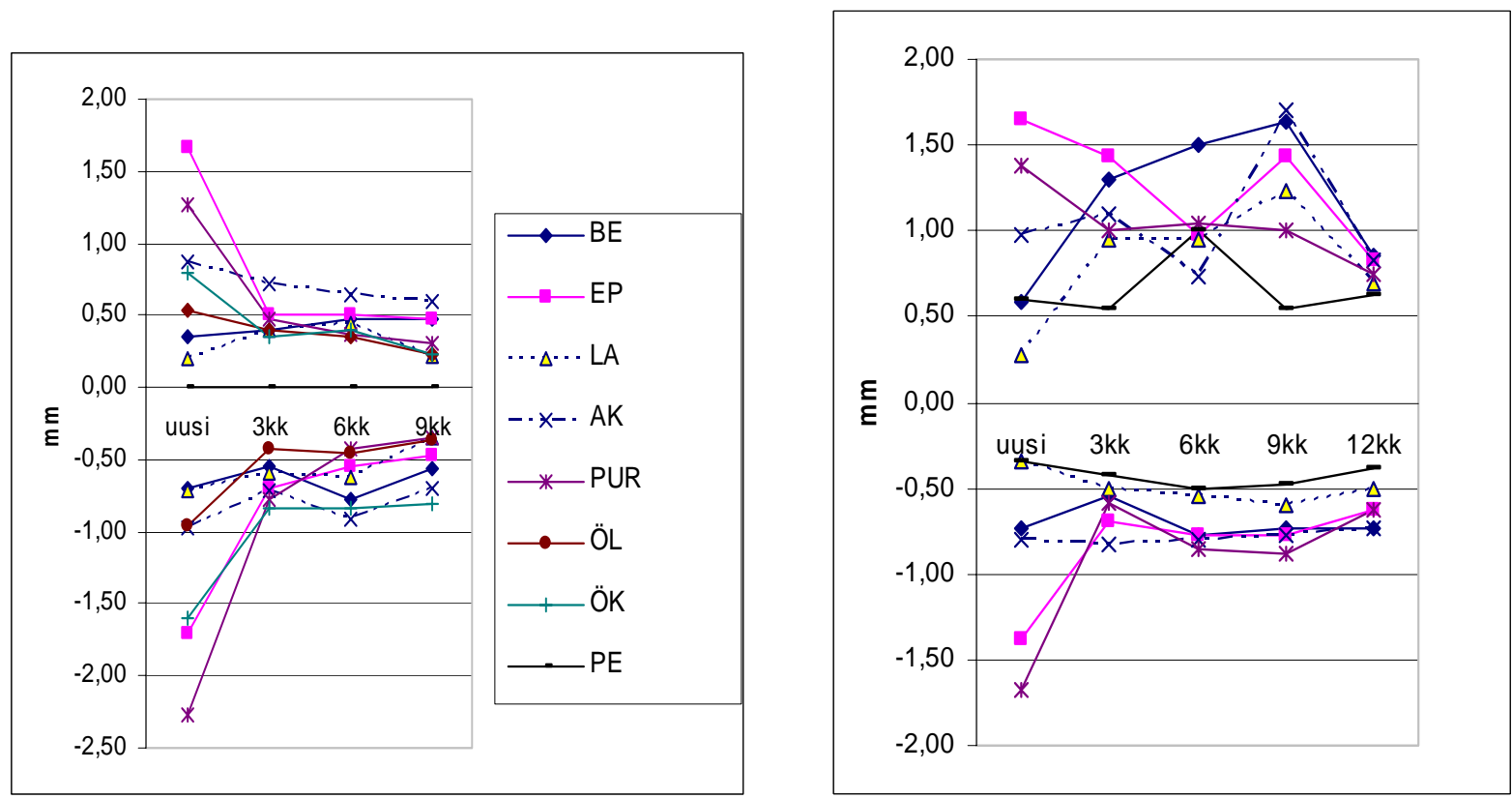

Kuva 2. Korkeimpien huippujen ja syvimpien kuoppien keskiarvot lattialla (vas.) ja ruokintapöydällä (oik.). 
Alustavien tulosten mukaan ruokintapöydän akryylipintanäytteiden väri muuttui 9 kk koejakson aikana vähiten (Taulukko 3). Ruokintapöydän koepalat oli mahdollista jättää kenttäkohteeseen vielä toisen vuoden ajaksi, joten vuoden 2008 lopussa on mahdollista tarkastella pidempiaikaisia muutoksia näissä pinnoissa.

Kaikki lattian koepalat pinttyivät ja tummuivat tasaisesti kenttäkokeen edetessä, mutta huokoiset teräshierretty ja silaani-impregnoitu betoni erottuivat muovipinnoitteista huonomman kosteuden hylkivyyden perusteella. Kaksi kerrannetta lattialle sijoitetuista öljypohjaisen pinnoitteen (ÖK) koepaloista kului osittain puhki 9 kk koejakson aikana. Laboratoriokokeiden perusteella muovipinnoitteet tasoittivat betonipintaa ja edistivät pinnan puhdistuvuutta (Määttä et al. 2007a,b). Laboratoriokokeiden perusteella arvioiden tiivistysaineella käsitellyn betonin puhdistuvuus oli kokonaisuutena vain keskitasoa eikä se myöskään ollut pinnaltaan kovin hylkivä. Koekappaleiden havaitut massan muutokset olivat pieniä (alle $1 \%$ ) ja niihin ovat vaikuttaneet monet tekijät.

Taulukko 3. Pintojen värin ja kiillon keskimääräiset muutokset navetan ruokintapöydällä ja lattiassa 9 tai 12 kk koejakson aikana (+ väri tummunut tai kiilto alentunut, - väri vaalentunut tai kiilto lisääntynyt, 0 ei selvää muutosta, * ko. materiaalia ei kohteessa)

\begin{tabular}{ccccc}
\hline Pintamateriaalin lyhenne & \multicolumn{2}{c}{ Ruokintapöytä } & \multicolumn{2}{c}{ Lattia } \\
\cline { 2 - 5 } & Väri & Kiilto & Väri & Kiilto \\
\hline BE & - & + & + & - \\
\hline EP & - & + & + & 0 \\
\hline LA & - & + & + & 0 \\
\hline AK & 0 & + & + & - \\
\hline PUR & + & + & + & - \\
\hline ÖL & $*$ & $*$ & + & - \\
\hline ÖK & $*$ & $*$ & + & 0 \\
\hline PE & + & 0 & $*$ & $*$ \\
\hline
\end{tabular}

\section{Johtopäätökset}

Alustavien tutkimustulosten perusteella kenttäkokeen materiaalien pintaominaisuudet muuttuivat pääsääntöisesti melko hitaasti. Pintojen tasaantumista tapahtui ja niiden kiilto sekä väri muuttuivat hiukan. Muutokset olivat monien materiaalien osalta erilaiset lattiassa ja ruokintapöydällä. Eniten muuttuivat teräshierretty ja silaani-impregnoitu betoni. Silaanikäsiteltyyn betoniin ei muodostu samanlaista pintakalvoa kuin muoveilla pinnoitettuihin betoneihin, joten ko. käsittely ei juurikaan parantanut betonilta kotieläintiloissa vaadittavia puhdistettavuusominaisuuksia. Muista pintamateriaaleista poiketen, toinen öljypohjaisista lattiapinnoitteista kului 9 kk koejakson aikana osin puhki. Tätä materiaalia ei ollut mukana kenttäkoetta edeltäneissä laboratoriokokeissa, joilla onkin tärkeä merkitys valittaessa materiaaleja kenttäolosuhteisiin.

\section{Kirjallisuus}

Baxter, S. 1984. Intensive Pig Production: Environmental Management and Design. 588 p. Granada Publishing Ltd, Great Britain.

De Belie, N. 1997. A survey on concrete floors in pig houses and their degradation. Journal of Agricultural Engineering Research 66, 151-156.

Kuisma, R. et al. 2008. New and traditional surface materials in cattle barns - a field study. Unpublished manuscript.

McClanahan, S.L. 2005. Preharvest food strategies in feedlot animal production. Brown-Brandl, T. (ed.) Proceedings of the Seventh international symposium Livestock Environment VII, 18-20 May 2005, Beijing, China. ASAE Publication nr 701P0205, USA. (pp. 621-628)

Määttä, J., Kymäläinen, H.-R., Mahlberg, R., Puumala, M., Kuisma, R., Uusi-Rauva, A., Hurme, K.-R. \& Sjöberg, A.-M. 2007a. Properties and cleanability of traditional and new agricultural surface materials: a laboratory study. NJF Conference, Proceedings, Copenhagen. 
Määttä, J., Kymäläinen, H.-R., Puumala, M., Mahlberg, R., Kuisma, R., Salparanta, L., Löija, M., Talibachew, A., Hurme, K.-R., Uusi-Rauva, A., Ritschkoff, A.-R. \& Sjöberg, A.-M. 2007b. Cleanability and properties of new and traditional surface materials in cattle barns. Agricultural and Food Science / accepted to be published..

Määttä, J. et al. 2008. Effect of wear on cleanability and properties of new and traditional surface materials in cattle barns. Unpublished manuscript. 